\title{
USE OF BIOLOGICAL TESTS FOR EVALUATION OF PESTICIDES
}

\author{
Eugene E. Kenaga
}

Dow Chemical USA, PO Box 1706, Midland, Michigan 48640, USA

\begin{abstract}
Biological tests are necessary for studying the toxicity and biochemical effects of pesticides to individual species in the animal and plant kingdoms as well as for indirect determination of biologically important physical and chemical properties of pesticides. Some of the more important requisites for meaningful application of biological tests are careful method standardization; use of sensitive sub-lethal indicators of toxicity; detailed knowledge of the life cycle and the environmental requirements of organisms; and proper interpretation and limitation of use of the data engendered.
\end{abstract}

\section{INTRODUCTION}

It is not necessary to explain or defend the need for and use of pesticides since man's difficulties with plagues of insects and other pests are well chronicled, even in the Bible. The addition of fine sand to grain was an effective control for granary weevils in the grain of ancient Egypt; however. it didn't add to the ease of ingestion of treated grain by humans. Because the use of pesticides necessitated additional effort or expenditure. man felt the need for increasingly better and efficient pest control early in his history. Obviously, better solutions were necessary for control of pests of man and his food. clothing and possessions. We are all aware of the many excellent chemicals available today for control of specific target pests. These chemicals. while mainly products of the 20th century, did not appear overnight. Intensified, successful development of organic pesticides has taken place principally since 1940 and ever since has caused a great deal of competition among chemical manufacturers. While the value of chemical analyses in combination with biological responses for interpretation of the effect of chemicals in the environment was soon apparent, the development of definitive analytical methods in the order of 0.1 p.p.m. was not common until the 1960 s. Until then most measurements and evaluations of toxicological and environmental effects were based on biological tests. Presently, the best evaluation techniques combine the use of biological and analytical test methods.

Historically, man's primary purpose in regard to the development of pesticides was to control the target organism. Upon discovering a new pesticide, he would then determine whether any effects occurred on nearby 'useful' non-target organisms. Upon the advent of widespread use of pesticides man discovered widespread persistent dispersion of certain chemicals 
such as DDT, as well as unfavourable effects on non-target species. Following these observations, considerable emphasis has been laid on determining the effect of chemicals on organisms in total ecosystems and the length of time necessary for eventual degradative alteration of pesticide molecules into naturally occurring components. Throughout this sequence of pesticide research and development, biological tests have been and still are playing an important part.

Bioassay tests are commonly in use, for example, for the measurement of acute and chronic toxicity; systemic activity in animals and plants; effects of contact, injection or dietary intake; volatility from surfaces; hydrolysis and effects of $\mathrm{pH}$; leachability in soil; stability against heat. radiation, etc., often before any analytical work is performed. Of course these tests may not establish the identity of the active compound (whether it be the original or altered molecule) which caused the observed effect. nor what quantity is involved.

Comparison of different compounds on given organisms, using a standardized test method, is the basis for selecting candidate pesticides from compounds of closely related or miscellaneous structures, and for determining specificity of pesticidal activity.

Biological tests are needed to measure toxicity of pesticide chemicals to organisms over a period of time. Such test organisms are often exposed to a sliding scale of changing concentrations in the environment rather than to a constant exposure as is used in many laboratory tests. If tested and the results interpreted correctly, organisms can be used to measure the sum of all of the toxic effects of the pesticide and its transformation products as modified by the environment.

These are only examples of the many uses to which biological tests may be put for evaluation of pesticides.

The subsequent discussion of the role which biological tests have played in the evaluation of pesticides will be divided into the following three major categories :

(1) Effects on target and non-target organisms;

(2) Distribution and fate of pesticides in the environment;

(3) Interpretation of data.

\section{BIOASSAY WORK WITH TARGET AND NON-TARGET ORGANISMS}

\section{Importance of test methods}

The assumed fact concerning a commercial pesticide is that it kills or controls the target organism long enough to gain economic or other tangible or intangible benefits. A considerable amount of 'hit-and-miss' field testing was done on an empirical basis in the early days of this century. By 1940 a number of chemical companies had established laboratory screening pesticide programmes to determine effects of many organic chemicals on representative organisms. Competitive screening necessarily resulted in limiting the number of organisms and protocols to the most definitive tests which would lead to control of the designated target organism. For this, and many other reasons, bioassay methods were developed in which the 
variables in the test methods were gradually limited, defined, and standardized for baseline day-to-day comparisons of a number of candidate pesticides. Early insecticide bioassay tests included, for example, the PeetGrady $^{1}$ test for measuring the speed of knockdown of the house fly, Musca domestica. Efforts of chemical industry members of the National Association of Insecticides and Disinfectants Manufacturers (NAIDM) to standardize this specific method occurred over a period of at least 15 years. It was found that any alteration in the standard methods for rearing the NAIDM strain of house fly such as changes in proportions of the dietary ingredients and moisture content, degree of larval media aeration, type and shape of larval media container, temperature, humidity, method of sifting pupae, and other unexpected and unthought of variables resulted in emergence of house fly adults of different weights, vigour, and susceptibility to insecticides.

The actual method of testing the adult fly depended upon a comparison with a standardized formulation of pyrethrum which had to be sprayed a specified length of time, in a specified series of motions, in a chamber of standard size and shape with specified openings and surfaces. The knockdown and mortality counts were taken at specified intervals and the knockeddown flies counted and collected in a definitive manner and held for postknockdown observation under defined conditions. In spite of all efforts to control variables, the knockdown results could easily vary 50 per cent from day-to-day when using a standard concentration of pyrethrum or other chemicals. Without test method standardization, the variation in results was much greater and more difficult to use for comparative purposes.

Procedures outlined for standardized fish toxicity tests include requirements for water quality (e.g. $\mathrm{pH}$ and hardness), temperature, fish species, size, and handling and other details ${ }^{2}$. Diet quality, a somewhat neglected study parameter, has been shown to alter the oral toxicity of various pesticides in rats. In rainbow trout fed various diets before treating the water with chlordane, the LC50 values varied over a fivefold range. A high protein pretest diet seemed to result in more chlordane tolerance in the fish ${ }^{3}$. See Table 1.

It is well known that microorganisms play a big part in the breakdown of pesticides in the environment. The test method conditions and species of microorganisms used in these tests are important as witnessed by the different metabolites formed from DDT when such conditions are altered. For example, entirely different metabolic routes for DDT may be taken under anaerobic conditions than under aerobic conditions. Microorganisms may

Table 1. Effect of diets on chlordane toxicity in rainbow trout ${ }^{3}$.

\begin{tabular}{lcc}
\hline \multicolumn{1}{c}{ Diet } & $\begin{array}{c}96-\mathrm{h} \mathrm{LC50} \\
(\mu \mathrm{g} / 1)\end{array}$ & $\begin{array}{c}95 \% \text { confidence } \\
\text { interval }\end{array}$ \\
\hline Oregon Moist & 8.2 & $6.1-11.0$ \\
Glencoe & 9.1 & $4.8-17.2$ \\
Silver Cup & 20.0 & $14.2-28.0$ \\
Ewos & 31.0 & $22.5-42.6$ \\
Low Protein $(23 \%)$ & 28.5 & $19.8-41.0$ \\
High Protein $(45 \%)$ & 47.0 & $37.7-58.5$ \\
\hline
\end{tabular}


alter DDT or metabolites by dechlorination (DDD, TDE), dehydrochlorination (DDE), oxidation of the methylene carbon (dicofol, DBP), or hydrogenation (DDNU) depending on environmental conditions $\mathrm{s}^{4,5}$.

The principle, which has since been illustrated repeatedly is that understanding the test methodology is the key to proper interpretation of any biological test result and that biological tests can be extremely variable. Despite their limitations, biological tests using identical standardized test conditions are still the main basis of establishing efficacy of a pesticide in comparison with a pesticide standard, whether under laboratory or field conditions.

\section{Knowledge of life cycles of organisms}

For many years prior to 1947 the use of chemicals for control of phytophagous mites was studied in the laboratory and field by counting the adult mite population for mortality on an acute contact basis (one to three days after application). With the advent of DDT and its use on fruit orchards and other plants mite populations appeared to take on a greater significance as a pest problem in treated orchards. Because of the great environmental stability of DDT, it appeared that test methods should be developed which would identify pesticides which might take days or weeks to show toxicity and which would take into account the entire life cycle of the organism. By extending the standard evaluation time for mite control from 3 days to 6 days in the laboratory, effects of chemicals on the egg hatching of mites could also be evaluated. By this small change in the test method it was found that some compounds previously reported as being poor acaricides, such as $p$-chlorophenyl $p$-chlorobenzene sulphonate (ovex) ${ }^{6}$, while not killing the adult life stage, was residual on foliage and did control the egg stage in the laboratory and field ${ }^{7}$. Such a compound thus interrupted the life cycle just as effectively as killing the adult stage and was therefore commercially useful.

In 1958, Mitlin and Barody ${ }^{8}$ suggested the use of the house fly (Musca domestica) as a screening organism to study candidate tumour-inhibiting compounds for prediction of human anti-tumour agents. The theory was that compounds interfering with cellular reproduction would also interfere with tumour cell formation, a correlation concept which was shown to be useful. Entomologists working with sterilization of insects by radiation were quick to perceive the potential of the test method for study of chemicals which were radio-mimetic for sterilizing insects.

Dried milk and sugar baits treated with chemicals fed on by the virgin adult house fly were used by La Brecque $e t$ al. ${ }^{9}$ in a test method to determine the production and fertility of eggs. Successful compounds were those which did not affect the adult, allowing sterilized insects to mate competitively with unsterilized adults, resulting in large reductions in numbers of flies of the next generation. This sterilization principle has since been applied to many species of insects.

A knowledge of the life history of an insect is sometimes useful to determine the weak point in its cycle. The drywood termite (Kalotermes minor) is an insect which may live in tunnels in underground wood or inside wooden 
parts of structures; thus access of fumigants is difficult. Fumigants such as methyl bromide which penetrate wood have been used for control of this pest. Methyl bromide, while reasonably successful in penetration of wood to kill these insects, caused objectionable odour problems due to methylation of sulphur compounds occurring in fumigated household commodities such as rubber, iodized salt, and proteinaceous foods. The demand for a non-odour forming fumigant resulted in the discovery of sulphuryl fluoride, a gas which also penetrates wood readily to kill drywood termites. Since infested wood usually contains all life stages of insects, the usefulenss of sulphuryl fluoride for the control of the insects was initially considered to be limited, for although it did kill the adult and nymphal stages it did not kill the egg stage of many species ${ }^{10}$. However, the successful use of the product to replace methyl bromide was assured when it was realized that nymphs hatching from eggs after fumigation needed the feeding attention of the parent in order to survive. Thus if the adults were killed, eggs need not be killed. Sulphuryl fluoride has thus found a unique use for control of the drywood termite.

Many other examples of studying the effect of chemicals on various plant or animal life stages are available as illustrated by herbicides (pre-emergent and post-emergent plant tests in soil, seed germination tests), fungicides, and other types of pesticides.

\section{Sensitive sub-lethal effects}

(a) Cholinesterase depression

A biological indicator of exposure at sub-lethal levels is a desirable safety feature for use of pesticides on target and non-target species of animals and plants. For most of the chlorinated hydrocarbon insecticides there is little observable advanced indication of toxicity to the organism, except perhaps by effects on reproductive parameters, which should be determined before usage becomes widespread. Fortunately, in the use of phosphate and carbamate insecticides, cholinesterase levels are good indicators of sublethal levels of exposure to animal organisms. For example, a 90-day feeding study on rats with chlorpyrifos showed some blood cholinesterase depression at 10 p.p.m. while there was no mortality at 300 p.p.m. indicating at least a 30 -fold safety factor ${ }^{11}$.

Undoubtedly there are other enzyme systems which will be found to be sensitive indicators of toxicity; however, many are not.

\section{(b) Enzyme induction}

The liver is a potent detoxifying organ in animals, particularly the microsomal enzyme fraction of endoplasm reticulum. In many animals subjected to toxicants the liver increases in size, partly in response to the need for increased metabolism activity in the liver caused by the introduction of foreign chemicals. Street ${ }^{12}$ reviewed the organochlorine insecticides and the stimulation of drug metabolism by liver microsome enzymes showing a number of examples in mammals. A classic pesticide effect is that of DDT on dieldrin metabolism when the two chemicals are fed jointly at low levels in the diet of rats. DDT markedly reduced the storage levels of dieldrin in 
tissues compared to dieldrin storage in the absence of DDT. Macek et al. ${ }^{13}$ found that a significant interaction also occurred in rainbow trout after 140 days of feeding DDT and dieldrin. In the pyloric caecae, the presence of dieldrin increased the rate of accumulation of DDT; conversely the presence of DDT decreased the rate of accumulation of dieldrin. While not so stated, enzyme reactions are a likely explanation of these changes just as they are in mammals. Without bioassay tests such interactions would not have been predicted on the basis of intake of each chemical separately.

The folic acid inhibitor 3-fluorophenyl alanine when fed at 1000 p.p.m. in a dried milk food preparation to the adult house fly before and during mating, caused all eggs laid to be sterile for the first week of egg production, after which normal fertility resumed even though the flies still ate the test $\operatorname{diet}^{14}$. Since this dosage did not kill the adult, it appears that the individual flies developed a new pathway, presumably enzymatic, to avoid, reverse, or destroy the reproduction-inhibiting effect of 3-fluorophenyl alanine.

\section{(c) Synergism}

It is now generally accepted that insecticide synergists act by blocking enzymes effecting insecticide detoxification and as a result they allow the insecticide to concentrate and exert its basic toxicity to a greater extent ${ }^{15}$. Especially important are the numerous oxidative reactions catalysed by the mixed-function oxidase complex of mammalian liver and various insect tissues. Synergism (as illustrated by more than additive mortality) has been shown to occur between methylenedioxyphenyl compounds such as piperonyl butoxide and pyrethrins in insects as a result of reduced metabolism rates of pyrethrum; and between EPN and malathion in mammals as a result of reduced metabolism rate of malathion. Synergism between the above chemicals was not predicted in advance and was discovered only by means of bioassay tests.

\section{DISTRIBUTION AND FATE OF PESTICIDES IN THE ENVIRONMENT}

\section{Biological tests as indicators of physical and chemical properties of pesticides}

Bioassay tests currently are not sufficient to completely assess the mode of action, and physical and chemical properties of pesticides. However, in initial screening and evaluation tests preceding analytical tests, bioassays are helpful in gaining insights as to these properties. As an example, four closely related $O, O$-dialkyl $O$-(3,5,6-trichloro-2-pyridyl) phosphates and phosphorothioates (see Table 2 for structures) were tested by four different bioassay techniques on the adult house fly (Musca domestica) (see Table 3) ${ }^{16}$. The bioassay results were later correlated with the vapour pressure, water solubility, adsorptive properties, and hydrolytic stability of the four compounds (see Table 4). The topical application of the four compounds in acetone illustrates the inherent toxicity to the house fly by contact to be in the following decreasing sequence: chlorpyrifos = chlorpyrifos methyl > DOWCO $180>$ fospirate. The water immersion test indicates by toxicity the water solubility and the relative hydrolytic stability of the two thiophos- 
Table 2. Structure of the four $O . O$-dialkyl $O$-(3.5.6-trichloro-2-pyridyl) phosphates and phosphorothioates $^{16}$.

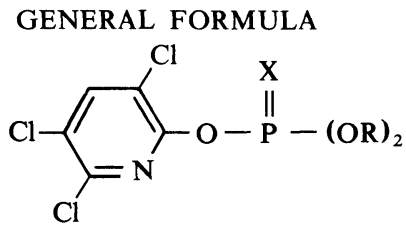

\begin{tabular}{llll}
\hline chlorpyrifos & DOWCO 180 & chlorpyrifos methyl & fospirate \\
\hline $\mathrm{X}=\mathrm{S}$ & $\mathrm{X}=\mathrm{O}$ & $\mathrm{X}=\mathrm{S}$ & $\mathrm{X}=\mathrm{O}$ \\
$\mathrm{R}=\mathrm{C}_{2} \mathrm{H}_{5}$ & $\mathrm{R}=\mathrm{C}_{2} \mathrm{H}_{5}$ & $\mathrm{R}=\mathrm{CH}_{3}$ & $\mathrm{R}=\mathrm{CH}_{3}$ \\
\hline
\end{tabular}

Table 3. Relative toxicity of the four compounds to the adult housefly using different test methods $^{16}$.

\begin{tabular}{lcccc}
\hline \multicolumn{1}{c}{ Compound } & $\begin{array}{c}\text { Topical } \\
\text { application }^{\mathrm{a}} \\
\text { LD95 } \\
(\mu \mathrm{g} / \text { /insect) }\end{array}$ & $\begin{array}{c}\text { Water } \\
\text { immersion }^{\mathrm{b}} \\
\text { LC95 } \\
\text { (p.p.m.) }\end{array}$ & $\begin{array}{c}\text { Vapour }^{\mathrm{c}} \\
\text { KD95 } \\
(\mathrm{min})\end{array}$ & $\begin{array}{c}\text { Duration } \\
\text { of } 95 \%^{\text {mortality }}\end{array}$ \\
\hline $\begin{array}{l}\text { chlorpyrifos } \\
\text { DOWCO 180 }\end{array}$ & 0.075 & 6.6 & 250 & 12 \\
$\begin{array}{l}\text { chlorpyrifos- } \\
\text { methyl } \\
\text { fospirate }\end{array}$ & 0.182 & 43.0 & 900 & 0.1 \\
\hline
\end{tabular}

Topical application of a solution in acetone to the thorax of the female fly.

b The insects were momentarily immersed in a water emulsion.

c Both males and females were held in untreated jars of 1 US gal capacity (about 3.8 litres), which were connected to jars of 1 US pint capacity (about 0.47 litre). The inner walls of the small jars were treated with the compounds at a level of $100 \mathrm{mg} / \mathrm{ft}^{2}(\mathrm{about}$ $\left.1.075 \mathrm{~g} / \mathrm{m}^{2}\right)$.

d Male and female flies were permitted to alight on a fir plywood panel, treated with insecticide at $40 \mathrm{mg} / \mathrm{ft}^{2}$ (approximately $150 \mathrm{mg} / \mathrm{m}^{2}$ ). that was hung. for $24-\mathrm{h}$ periods. inside an untreated wide-screen cage at various intervals of time after the application of the insecticide. The figures in the column show the time in weeks (i.e. the time after the treatment of the panel) at the end of which $95 \%$ mortality was still obtainable.

phates compared to the two phosphates: chlorpyrifos $\cong$ chlorpyrifos methyl $\gg$ DOWCO $180>$ fospirate. Mortality from vapours from relatively nonsorptive glass indicates the following decreasing order of volatility: chlorpyrifos methyl $>$ chlorpyrifos $>$ fospirate $=$ DOWCO 180 . The residual nature of these insecticides on a flat piece of plywood illustrates the effect of an adsorptive binding surface on reduction of volatility, as shown by the duration in weeks of fly kill as follows: chlorpyrifos $>$ chlorpyrifos methyl $>$ DOWCO $180>$ fospirate. These bioassay results compare well with the respective physical and chemical properties of the above compounds as shown in Table 4.

The vapour pressure of a compound can be measured by various standardized techniques and expressed as a precise figure at a given (room) temperature 
Table 4. Some properties of the four $O . O$-dialkyl $O$-(3.5.6-trichloro-2-pyridyl) phosphates and phosphorothioates ${ }^{16}$.

\begin{tabular}{|c|c|c|c|c|}
\hline Property & Chlorpyrifos & DOWCO 180 & $\begin{array}{l}\text { Chlorpyrifos- } \\
\text { methyl }\end{array}$ & Fospirate \\
\hline $\begin{array}{l}\text { Vapour pressure at } 25^{\circ} \mathrm{C} \\
\left(\mathrm{mmHg} \times 10^{-5}\right)\end{array}$ & 1.87 & - & 4.22 & 0.42 \\
\hline $\begin{array}{l}\text { Solubility in water at } \\
23-25^{\circ} \mathrm{C} \text { (p.p.m.) } \\
\text { Hydrolysis in } 50 \% \mathrm{v} / \mathrm{v} \\
\text { methanol/water solution at } \\
23^{\circ} \mathrm{C} \text {. halflife (days) at the } \\
\text { following pH values: }\end{array}$ & 0.4 & $520(\mathrm{ca})$ & 4.0 & $300(\mathrm{ca})$ \\
\hline $\mathrm{pH}=5$ & 1100 & $>85$ & 10 & 5.3 \\
\hline $\mathrm{pH}=6$ & 1600 & - & 40 & - \\
\hline $\mathrm{pH}=7$ & 350 & 6.3 & - & 0.63 \\
\hline $\mathrm{pH}=8$ & 55 & - & 3 & - \\
\hline $\mathrm{pH}=9$ & 30 & 0.71 & $<3$ & 0.63 \\
\hline
\end{tabular}

at sea-level pressure $(760 \mathrm{mmHg})$. These data are useful where molecules are volatilizing from a liquid or solid mass of the same compound. However, when a pesticide is applied at a uniform dosage rate to heterogeneous surfaces such as water, soil, foliage, wood or glass, volatility seems to be variable. A compound such as chlorpyrifos which has a low vapour pressure ${ }^{16}$ can be very persistent on dry wooden surfaces and in dry organic soil, and relatively non-persistent on green foliage surfaces as judged by bioassay tests ${ }^{17}$. Volatility appears to be governed in part by adsorption to the surface with which the pesticide molecule comes into contact. In contrast a compound such as tricyclohexyltin hydroxide which in the dry state has a vapour pressure so low that it is essentially unmeasurable, can be shown to kill spider mites infesting a bean plant by transfer of its vapours from inside a treated glass jar covering but not touching the plant ${ }^{18}$. By use of radioactive ${ }^{119} \mathrm{Sn}$, tricyclohexyltin hydroxide was later shown to codistil with water, thus explaining the vapour transfer to the mite-infested foliage indicated by the bioassay ${ }^{19}$.

During the 1939-45 war stockpiles of wheat and corn were stored in large bins and warehouses throughout the mid-USA. Insect infestations soon necessitated treatment by liquid fumigation through application to the top surface area of large masses of the grain. This insecticidal use depended on penetration of the gases to all depths of grain. It was found that when carbon tetrachloride or carbon disulphide were poured on the surface of the grain in the bin, insects would be killed in the bottom of the bin, but not in the top area where the fumigant was applied. In order to solve the problem of killing insects throughout the bin, laboratory bioassay tests were initiated using upright drain pipes as simulated grain towers or bins. Holes were drilled in the side through which tightly fitting plastic slotted vials containing grain insect species were placed at various depths for measuring fumigant insecticidal penetration of the grain. Ethylene dichloride was found to do a good job of killing insects in the central mass of the grain but not at the top or bottom. Since the boiling points of carbon tetrachloride 
$\left(76.8^{\circ} \mathrm{C}\right)$ and ethylene dichloride $\left(83.5^{\circ} \mathrm{C}\right)$ are similar, it became apparent that the compounds had different adsorption properties on grain. Fletcher and Kenaga ${ }^{20}$ used this principle to test mixtures of fumigants by the grain tower bioassay method and patented mixtures containing ethylene dibromide, ethylene dichloride and carbon tetrachloride. Among these three fumigants, vapours would penetrate and kill insects at all depths in the grain including the surface. This was perhaps one of the earliest commercial uses of the principle of what later became known as gas chromatography, which in turn was used so successfully in the 1960s and 1970s as a sensitive pesticide analytical tool.

Methods of studying and interpreting effects on target organisms do not need further dicussion here since most government agencies which register pesticides for use are knowledgeable in biological test method requirements, especially where the criteria of evaluation is mortality of the visibly damaging life stages of target organisms.

\section{Bioconcentration}

Bioconcentration of food and nutrients which are directed to the right places at the right time is a basic necessity for living organisms. Temporary bioconcentration of pesticides occurs partly because they mimic in some way essential molecules in the organism and are caught up in an essential transport system and distributed preferentially on or in some specific tissue. Bioconcentration becomes possible when the molecule is relatively stable in certain tissues of the organism.

DDT is the first pesticide molecule to receive prominence for bioconcentration properties, particularly in fat tissues. The widespread distribution of DDT in $10^{-12}$ (p.p.t.) quantities in Lake Michigan and many other bodies of water would not have been detected by analytical methods in use in the 1960 s had it not been found concentrated to $10^{-6}$ (p.p.m.) quantities in fat tissues in fish and birds ${ }^{21}$. Organisms act as filters and bioconcentrate pesticides in certain tissues depending on the physical, chemical and biochemical properties of the compound ${ }^{5}$. Obviously, because it is an effective pesticide, DDT (or its metabolites) are concentrated to lethal quantities in some species of organisms.

Fish bile analyses have shown the concentration of carbaryl, and the lampreycide 3-trifluoromethyl-4-nitrophenol, and DDT (to a lesser extent) in rainbow trout to rise to as much as a 1000-fold ratio (bile to water) when exposed to treated water for 24 hours $^{22}$. These three compounds have very different properties from the structural and chemical standpoint and similar bioconcentrations would not be expected. Thus, discovery and use of the phenomenon of bioconcentration of chemicals in certain tissues of animals or plants is of great benefit in monitoring pesticides in the environment.

An interesting use of chromatographic techniques which occurred because of the development of highly sensitive analytical techniques is the method requiring the use of glass plate thin-layer soil chromatography as a bioassay tool for determining relative leaching characteristics of herbicides in soils. In this new test method the herbicide is applied as a streak to the bottom of the soil-coated plate and then eluted with water. After elution the 
position of the herbicide on the plate may be determined by bioassay by growth of browntop grass (Agrostis tenuis) ${ }^{23}$ or green alga (Chlorella sorokiniana $)^{24}$ on the eluted soil plate. This test avoids the serious disadvantage of the normal use of soil columns for determination of movement of herbicides in soil which has a poor reproducibility factor because packing of soil columns results in channelling of water between the soil and the walls of the containing tube.

\section{INTERPRETATION OF TOXICITY DATA}

The use of the acute oral LD50 test has become universally (and incorrectly) accepted as a key indicator of the comparative toxicity of chemicals to mammals and birds. Because of this acceptance, toxicologists, lawyers and administrators all have their own particular uses for acute oral LD50 data. The acute oral LD50 value has evolved into a standardized piece of data which enters into legalized documents, laws, regulations and court suits, and is used to resolve matters which are of great economic or political importance.

The acute oral LD50 test method involves the application of a single oral dose to each animal in a group, using varying dosage series to obtain a calculated dosage that would be expected to kill 50 per cent of animals treated. The original purpose of the acute oral LD50 value was to establish a toxicity baseline for comparison of various compounds on rats, mice or other laboratory animals for use in interpreting the hazard of the material when swallowed in concentrated form by man. This is a valid use. However, such data are sometimes incorrectly extrapolated to represent toxicity from acute dietary intake (LC50) or chronic exposure, not only to man, but to wildlife. One reason this misuse is critical is because government agencies place emphasis on environmental effects in regulating the use of pesticides. A number of agencies has used the acute oral LD50 value as a false index of hazard for birds and mammals. This misuse sometimes results in classifying a pesticide in a restricted category, although the compound may have been proved to be safe to birds and mammals in dietary treatments in the laboratory and under field conditions.

Just as important is the opposite case where the acute oral LD50 data indicates a compound to be safe, whereas the LC50 dietary treatment (which simulates the normal intake of pesticides in environmental food by wildlife) indicates more correctly that it is much less safe or even unsafe ${ }^{25}$. Data in Table 5 illustrate the principle that the acute oral LD50 is not toxicologically equivalent to the dietary LC50 and therefore the acute oral LD50 is not a proper measure for determining the toxicological hazard of a compound to wildlife.

For example, in Table 5 DDT and dieldrin appear much safer to mallards by the acute oral test than by the dietary feeding test, based on per day or total amount consumed for 50 per cent mortality. In contrast, mexacarbate looks very toxic by means of the acute oral test and quite safe by the dietary feeding test. Chlorpyrifos appears to be intermediate in that mallards eat slightly less in the dietary test than in the acute oral test in 1 day but slightly more in 5 days for the 50 per cent mortality level. 


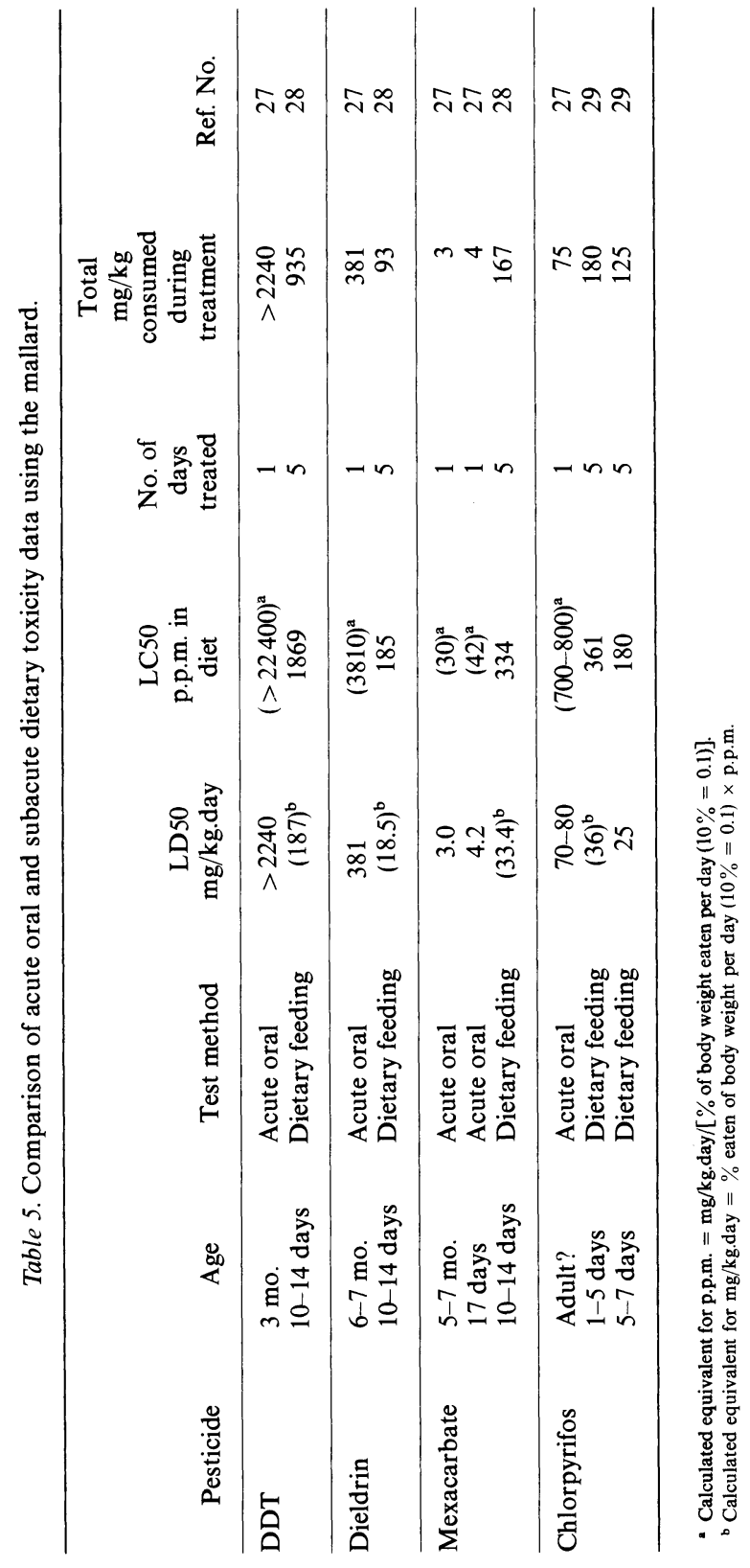


EUGENE E. KENAGA

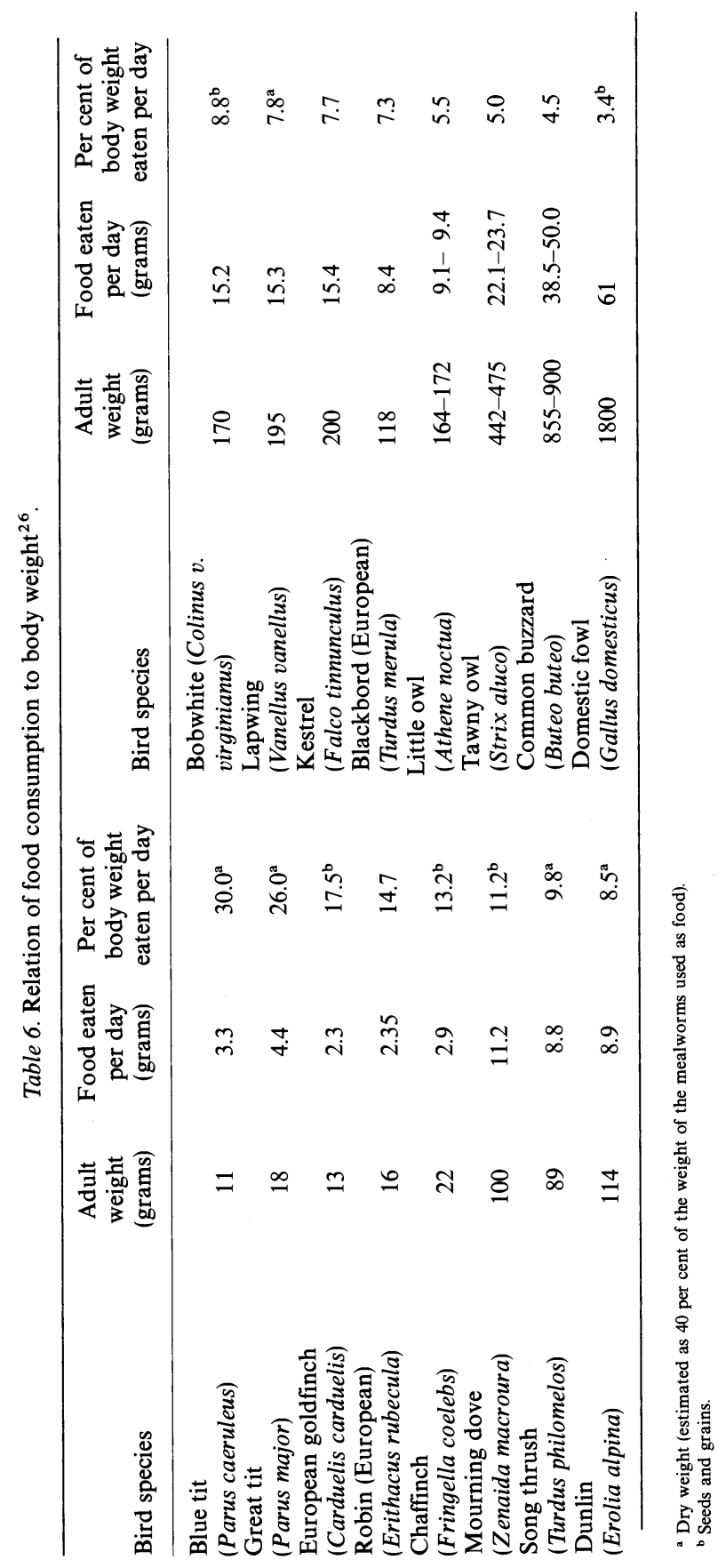


There are major differences in toxicity of a given chemical to various phylla, orders and species of animal organisms when fed in their diets. Perhaps not so well known is the effect of variation in weights of birds (or fish or mammals) on the dietary intake of pesticides as a result of variations in food consumption. Great variations in food consumption can result between bird species of different adult weights (see Table 6) ${ }^{26}$ and also between stages of growth of a given species (see Table 7$)^{25}$ since the food intake as a percentage of the body weight of birds generally increases as the body weight decreases. The significance of this lies in the $\mathrm{mg} / \mathrm{kg}$.day intake of pesticide. Assuming the above weight relationship to dietary intake and pesticide residue in each bird's diet to be equal, the smaller bird will usually consume a larger $\mathrm{mg} / \mathrm{kg}$.day intake of pesticide, sometimes by a tenfold factor, over a large bird ${ }^{25}$.

Table 7. Relationship of food consumption to body weight and age in the Bobwhite and the Broad-breasted bronze turkey ${ }^{25}$.

\begin{tabular}{lcc}
\hline $\begin{array}{c}\text { Age } \\
\text { (weeks) }\end{array}$ & $\begin{array}{c}\text { Average } \\
\text { weight } \\
\text { (grams) }\end{array}$ & $\begin{array}{c}\text { Per cent of } \\
\text { body weight } \\
\text { eaten per day }\end{array}$ \\
\hline Bobwhite $^{\mathrm{a}}$ & & \\
$0-1$ & 11.2 & 26.3 \\
$1-2$ & 18.6 & 23.4 \\
$2-2.5$ & 31.7 & 15.7 \\
Domestic turkey & & \\
$0-1$ & 88 & 13.6 \\
$1-2$ & 184 & 13.1 \\
$2-3$ & 338 & 11.3 \\
$3-4$ & 533 & 9.1 \\
$4-8$ & 1315 & 7.8 \\
$12-16$ & 4944 & 5.6 \\
$16-28$ & 7507 & 4.0 \\
\hline
\end{tabular}

${ }^{a}$ From a report of The Dow Chemical Company.

b Modified from the Salisbury Poultry Product Use Guide, Salisbury Literature. Charles City. Iowa.

- Turkey mash not corrected for dry weight.

Many test methods have been developed to assess the effect of pesticides on target and non-target organisms. Chemicals, such as mutagens or carcinogens which affect organisms at the cellular level or chemicals which cause delayed effects, such as those on reproduction, are treated with great emotion. Published test results which under any circumstances indicate that these abnormal types of effects can be engendered by a given chemical places that chemical under a cloak of suspicion, which, whether justified or not, cannot be dispelled in some people's judgement or by contradictory results from other valid tests.

The use of the chicken's egg as a measure of teratogenicity of pesticides by injection prior to incubation ${ }^{30}$ is a good example of a test method which can generate misleading data which have great emotional impact. Malathion was found to have teratogenic (monster formation) effects when evaluated by this test method. This and similar tests with other compounds showing teratogenic effects on chick embryos have caused alarm among certain 
toxicologists and government officials. Commercial use for many years and many toxicological tests on mammals with malathion have not revealed any teratological effects on humans or other mammals. In this test method untreated eggs can exhibit teratological effects from improper incubation and handling, damage by needle or solvent, etc. In addition, the chicken egg embryo has no way of excreting the pesticide or its metabolites in contrast to other life stages of birds.

The egg injection test method continued to be used as late as 1971, when in one test ten organophosphate insecticides were injected into chicken, Chukar, and bobwhite eggs, all causing teratogenic effects ${ }^{31}$. Test diets containing 25-100 p.p.m. of the same organophosphate insecticides, which when fed to these same three species of birds for 100 days, failed to produce teratogenic effects. Based on residue studies, the authors state that it appears probable that the majority of these pesticides are metabolized and ... never reach the eggs'. Since exposure of birds to pesticides is generally through the diet, not through direct contact with the egg embryo, the practicality of such a test is limited and publication of results of such tests in today's emotional climate creates an atmosphere of fear and indecision through the use of the 'red flag word' teratology. This misleading information in turn creates an unnecessary and costly obstacle to the registration of the pesticide for useful safe purposes.

\section{SUMMARY}

Biological tests are useful for determining the degree and mode of toxicity of a chemical to specific plant and animal organisms, or for bioassay, for determining the presence of a toxic residue. Most tests have been done primarily on target pest organisms and secondarily on important non-target species. The test method used for comparative purposes must be standardized since variations in many parameters of the test methods have been shown to influence results. Biological evaluation of pesticides needs to take into account the susceptibility of various stages of the life cycle of the organism as well as the environment of the organism. Enzymatic and other biochemical responses are useful in measuring the non- or sub-lethal effects of pesticides as well as subtle morphological or cellular changes such as teratogenic, mutagenic or reproductive effects. The mobility and persistence of pesticides or metabolites can be bioassayed to help evaluate leaching, volatility, sorption, residual toxicity, hydrolysis, and combinations of these properties.

Interpretation of simplified laboratory biological tests, while useful, rarely accounts for all of the significant variables in field tests since constant changes in organisms and in pesticide residue levels occur in the field tests. It is easy to oversimplify evaluation of pesticides by use of measurements from biological test methods which are misleading or are wrongly interpreted. Government regulations and test method protocols must be developed which can suitably be used to evaluate the unique biological, physical and chemical properties, and the use pattern of each candidate pesticide. Biological tests are usually most useful when matched by analytical identification and quantification of pesticide residues or metabolites related to environmental or toxicological aspects of the problem being investigated. 


\section{REFERENCES}

1 C. H. Peet and A. G. Grady. J. Econ. Ent. 21, 612 (1928).

2 American Public Health Association, Inc. Standard Methods for the Examination of Water and Waste Water. New York (1971).

${ }^{3}$ P. M. Mehrle, W. Johnson and F. L. Mayer Jr. Given at Midwest Fish and Wildlife Conference, St Louis, Missouri. (3-5 December 1973).

${ }^{4}$ F. Matsumura. Envir. Quality and Safety, 1, 96 (1973).

5 E. E. Kenaga. Residue Reviews. 44, 73 (1972).

${ }^{6}$ R. L. Metcalf. J. Econ. Ent. 41, 875 (1948).

7 E. E. Kenaga and R. W. Hummer. J. Econ. Ent. 42, 966 (1949).

8 N. Mitlin and A. M. Barody. Cancer Res. 18, 708 (1958).

9 G. C. LaBrecque, P. H. Adcock and C. N. Smith. J. Econ. Ent. 53, 802 (1960).

10 E. E. Kenaga. J. Econ. Ent. 50, 1 (1957).

11 Food and Agriculture Organization, United Nations. 1972 Evaluation of Some Pesticide Residues on Food. p 149. Rome (1973).

12 J. L. Street. Ann. NY Acad. Sci. 160, 27 (1969).

${ }^{13}$ K. J. Macek, C. R. Rodgers, D. L. Stalling and S. Korn. Trans. Amer. Fisheries Soc. 99. 689 (1970).

14 E. E. Kenaga. Unpublished data, The Dow Chemical Company, Midland, Michigan (1964).

15 C. F. Wilkinson. Bull. World Hlth. Org. 44, 171 (1971).

16 E. E. Kenaga. Bull. World Hlth. Org. 44, 225 (1971).

17 E. E. Kenaga, W. K. Whitney, J. L. Hardy and A. E. Doty. J. Econ. Ent. 58, 1043 (1965).

18 W. K. Whitney and E. E. Kenaga. Unpublished data, The Dow Chemical Company, Midland Michigan. April (1966).

19 G. N. Smith, F. S. Fischer and R. J. Axelson. Unpublished data. The Dow Chemical Company, Midland, Michigan. (1970).

20 F. W. Fletcher and E. E. Kenaga. US Pat. No. 2391890 . (1 January 1946).

21 H. E. Johnson and R. C. Bell. Advances in Chemistry Series No. 111, p 1. American Chemical Society: Washington, DC (1972).

22 J. J. Lech, S. K. Pepple and C. N. Statham. Tox. Appl. Pharmacol. 25, 430 (1973).

23 T. Chapman, P. A. Gabbott and J. M. Osgerby. Pesticide Science, 1, 56 (1970).

24 C. S. Helling, D. F. Kaufman and C. T. Dieter. Weed Science, 19, 685 (1971).

25 E. E. Kenaga. Environmental Quality and Safety, 2, 166 (1973).

26 M. M. Nice Bird-Banding, 9, 1 (1938).

27 R. K. Tucker and D. G. Crabtree. Handbook of Toxicity to Wildlife. Resource Publication No. 84. Supt. of Documents, US Government Printing Office: Washington, DC (1970).

${ }^{28}$ R. G. Heath, J. W. Spann, E. F. Hill and J. F. Kreitzer. Spec. Sci. Rep. Wildlife No. 152. US Dept of Interior: Washington, DC (February 1972).

29 E. E. Kenaga. Residue Reviews. 50, 1 (1974).

30 J. P. Marliac and M. K. Mutchler. Fed. Proc. 22, 188 (1963).

31 U. K. Abbott and N. E. Walker. Summary Report 1971, p 9. Food Protection and Toxicology Center; University of California: Davis, California (1971?). 